\title{
Substantia nigra 6-OHDA lesions mimic striatopallidal disruption of syntactic grooming chains: A neural systems analysis of sequence control
}

\author{
KENT C. BERRIDGE \\ University of Michigan, Ann Arbor, Michigan
}

\begin{abstract}
It has been suggested that the coordination of complex sequences of behavior requires normal nigrostriatal function. A previous study showed that kainic acid lesions of the corpus striatum can disrupt the performance of natural, untrained stereotyped sequences (syntactic chains), which occur regularly during normal rodent grooming. In this study, intranigral injections of 6-OHDA were used to destroy nigrostriatal dopamine projections in order to deplete the striatum of dopaminergic inputs. Striatal dopamine depletion was found to disrupt the effective completion of syntactic grooming chains. Syntactic chain disruption was correlated with the aphagia that follows dopamine depletion. These data were compared with those from previous studies of chain completion after striatal damage, after sensory deafferentation, and after decerebration at various levels of the brainstem. These comparisons indicated that the loss of either dopamine projections or intrinsic striatal neurons produced equivalent disruption of syntactic grooming chains. It also showed that loss of either component of the nigrostriatal system disrupted chaining to a degree equal to that produced by loss of the entire forebrain. These results suggest that the integrity of nigrostriatal systems is crucial to forebrain implementation of this stereotyped sequence.
\end{abstract}

The system formed by the corpus striatum (caudateputamen and globus pallidus), and its connections with the substantia nigra, cortex, and thalamus, has long been recognized as crucial to motor function. Clinical diseases (e.g., Huntington's chorea, Parkinson's and Wilson's diseases, and certain tardive dyskinesias) of the nigrostriatal system or of its connections produce profound behavioral disturbances. Yet these disorders are difficult to characterize in terms of simple motor deficits and, in comparison to other "motor structures" such as precentral cortex, the motor functions of the nigrostriatal system remain poorly understood.

It seems clear, however, that the role of this system goes beyond the coding of elementary actions. Although single units within the striatum have been found to fire in conjunction with the performance of simple movements (e.g., Aldridge, Anderson, \& Murphy, 1980; Anderson \& Horak, 1985; Crutcher \& DeLong, 1984; DeLong, 1971), such simple movement-linked cells are relatively rare in the striatum in comparison to their frequency in the primary motor cortex (Lidsky, Manetto, \& Schneider, 1985; Rolls \& Williams, 1987). A number of investiga-

This project was supported by National Institutes of Health Grant NS 23959. I am very grateful to I. L. Venier for 6-OHDA group maintenance, and to T. E. Robinson for the dopamine histological analysis. Requests for reprints should be sent to Kent C. Berridge, Department of Psychology, University of Michigan, Neuroscience Laboratory Building, Ann Arbor, MI 48109. tors have proposed that nigrostriatal systems are more closely concerned with the organization of movement into coordinated sequential patterns than with the production of motor elements. This hypothesis has arisen largely from studies of animals with striatal damage but has also been supported by clinical observations. For example, nigrostriatal Parkinson's patients show particular deficits in certain sequential movement tasks (Benecke, Rothwell, Dick, Day, \& Marsden, 1987; Stelmach, Worringham, \& Strand, 1987), and cortical lesions of Broca's area that produce sequentially recurring utterances may generally be accompanied by additional striatal damage (Brunner, Kornhuber, Seemüller, Suger, \& Wallesch, 1982).

The present study focused upon the role of nigrostriatal circuits in the control of natural, species-specific sequences of action. Species-specific action patterns provide an opportunity for examining the neural control of complex coordinated action within the natural behavioral context that brain systems have evolved to control. A rich variety of coordinated sequential patterns occur in rodent grooming (Berridge, Fentress, \& Parr, 1987; Fentress, 1972; Richmond \& Sachs, 1978). One of the most highly structured of these sequential patterns is a "syntactic" (Lashley, 1951) chain that organizes many individual forelimb stroke and lick actions into four stereotyped phases (Figure 1; Berridge \& Fentress, 1986). This stereotyped chain is specified by neural systems residing primarily in the brainstem (Berridge, 1989) and is largely independent of any need for peripheral sensory feedback (Ber- 


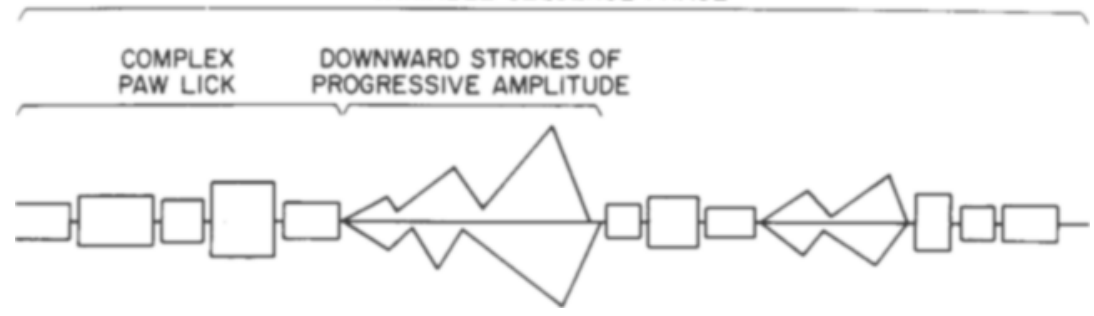

STEREOTYPEO SEQUENCE PHASE

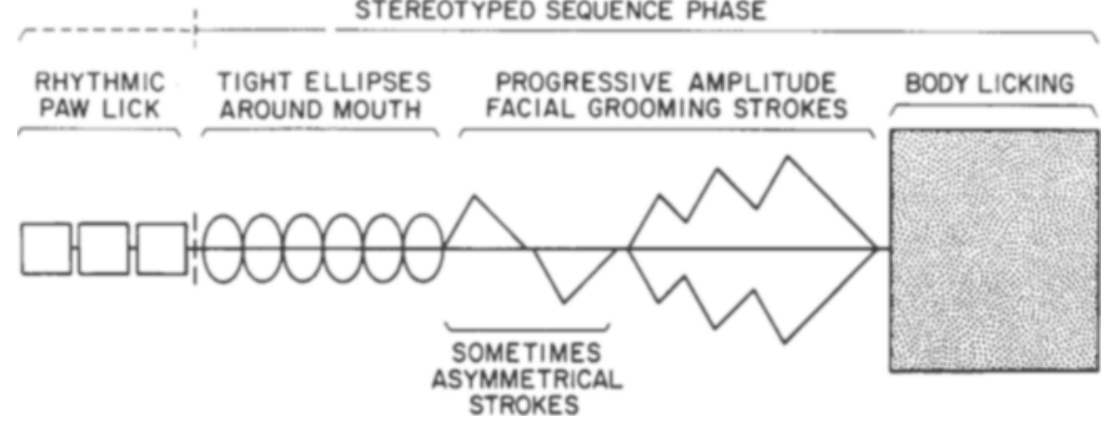

Figure 1. Idealized schematic notations of sequentially flexible (top) and syntactic chain (bottom) modes of facial grooming. Time proceeds from left to right. Diagonal deviations above and below the horizontal axis denote movements of the two forepaws along the face and away from the nose (axis). Open squares denote paw licks; filled square denotes body lick. Chain phases are (1) tight ellipses around the mouth; (2) asymmetrical or unilateral strokes; (3) bilateral, large-amplitude strokes; and (4) body licking.

ridge \& Fentress, 1987a). Yet a study of striatopallidal involvement in the coordination of this highly structured sequence showed that completion depended significantly upon the integrity of striatal circuits. Extensive loss of intrinsic striatopallidal neurons from either the anterior or the posterior corpus striatum reduced the percentage of chains that were completed syntactically to approximately half the normal level (Berridge \& Fentress, 1987b). This observation of disruption supports the proposition that the syntactic structure even of natural and untrained behavioral sequences depends to a large degree upon striatopallidal function (Bury \& Schmidt, 1987; Cools, 1985; Schmidt, 1984).

There are a number of ways by which striatal and related systems might exert control over this instinctive sequential pattern. Different investigators have suggested nigrostriatal involvement in sequencing to be either direct, via the generation and initiation of centrally programmed sequences of action (Cools, 1985; Evarts, Kimura, Wurtz, \& Mikosaka, 1984; Jaspers, Schwartz, Sontag, \& Cools, 1984; Marsden, 1982), or indirect, via the hierarchical modulation of sensorimotor loops and central pattern generators (Abercrombie \& Jacobs, 1985; Berridge \& Fentress, 1987b; Cools, 1985; Iverson, 1979; Lidsky et al., 1985; Schneider, 1984, 1987). Hypotheses of direct striatal generation of patterning would suggest that these neurons participate in the actual specification of the serial order that constitutes the pattern. Such hypotheses would account for chain disruption after striatal lesions on the grounds that the syntactic rule itself cannot be properly generated in the absence of these neurons. Hypotheses of indirect hierarchical modulation would suggest that the striatum normally functions to modulate sensorimotor loops and to switch control between competing centrally generated signals and external sensory cues. According to this view, chain disruption would occur after striatal damage because distracting sensory events would fail to be suppressed during chain execution, and so could successfully compete with chaining and cause grooming to revert to a sequentially flexible or stimulus-guided mode (Berridge \& Fentress, 1987b).

Whether striatopallidal circuits participate directly in the actual generation of chain sequential structure or instead act hierarchically to implement patterns generated entirely elsewhere, it is clear that no single brain structure alone can be assigned responsibility for the coordination of high-level behavioral patterns. Rather, a systems view that incorporates afferent and efferent connections is required to understand how separate structures interact to form coordinating complexes.

Ascending projections from dopamine neurons within the substantia nigra and ventral tegmentum form a crucial component of striatal systems. These dopamine projections are likely to participate in any striatopallidal control of sequential coordination, whether it be through pattern generation or sensorimotor modulation. Regarding pattern generation, Divac (1975, cited in Divac, Öberg, \& Rosenkilde, 1987) has argued for a role of sub- 
stantia nigra dopamine projections by distinguishing between pattern coding neuronal functions and permissive or rate-setting ones. Divac and his colleagues suggest that coordination of the patterned activity of striatal neurons arises through intrinsic circuits and cortical connections, but that this requires the presence of dopaminergic afferents "setting the stage, as it were, for the patterned activity of the neostriatum" (Divac et al., 1987, p. 62). Arriving at a similar conclusion from a different direction, Marsden (1980) has suggested that "the lesion that disrupts normal basal ganglia function most effectively is inactivation of the dopaminergic input from the midbrain" (p. 285) and that motor programming is impaired in the absence of this input.

A role for nigrostriatal projections in the control of sensorimotor responsiveness also has been indicated by many experiments (e.g., Fairley \& Marshall, 1986; Marshall, Turner, \& Teitelbaum, 1971; Schallert \& Hall, 1988; Schallert, Whishaw, De Ryck, \& Teitelbaum, 1978; Ungerstedt, 1971; Whishaw, O'Conner, \& Dunnett, 1986; Whishaw \& Tomie, 1988) and by clinical observations (e.g., Schneider, Diamond, \& Markham, 1986). A number of these studies have shown that the processing of oral and facial sensory information, which might be especially potent distractors or control signals for a facial grooming sequence, is influenced by nigrostriatal manipulations (Caligiuri \& Abbs, 1987; Huston, Morgan, Lange, \& Steiner, 1986; Schallert \& Hall, 1988; Schneider, 1984). The hyporesponsiveness that follows nigrostriatal damage has been well documented by these investigations, but it also appears that a sensorimotor hyperresponsiveness can be seen in certain Parkinson's patients (e.g., Caligiuri \& Abbs, 1987) and in striatum-damaged animals (e.g., Berridge, Fentress, \& Treit, 1988). Such bidirectional changes in sensorimotor responsiveness are consistent with the hypothesis that lesions disrupt dynamic sensorimotor modulation: programmed increases and decreases of sensorimotor responsiveness from baseline levels both should be affected. Finally, it has been shown that at least some impairments of sensorimotor function are produced similarly by intrinsic lesions (kainic or ibotenic acid) and by dopamine denervation (6-OHDA) of the striatum (Dunnett \& Iverson, 1982; Whishaw et al., 1986). These points lead to the prediction that striatal control of grooming sequences is likely to be shared by ascending components of the nigrostriatal system.

In this study, the necessity of substantia nigra dopamine projections to the striatum for the performance of syntactic grooming chains was examined. Rather than damaging the striatum directly, injections of 6-hydroxydopamine (6-OHDA) were made bilaterally into the substantia nigra in order to remove dopamine projections, and the resulting effects on chaining were assessed. To better evaluate the results within the context of a larger systems anal$y$ sis, these effects were also compared explicitly to those that follow other neural manipulations relevant to the execution of natural grooming chains: striatal lesions, sen- sory deafferentation, and decerebration at various brainstem levels.

\section{METHOD}

\section{Surgery}

Twenty-seven male Sprague-Dawley rats were anesthetized with ketamine $(100 \mathrm{mg} / \mathrm{kg}, \mathrm{i} . \mathrm{m}$.$) and acepromazine (1 \mathrm{mg} / \mathrm{kg})$ and injected with bicillin $(30,000$ units, i.m.) and atropine sulfate ( $1 \mathrm{mg} / \mathrm{kg}$, i.p.) prior to surgery.

Bilateral skull holes were drilled $5.0 \mathrm{~mm}$ posterior to bregma and $2.0 \mathrm{~mm}$ lateral to midline, with bregma and lambda in the same horizontal plane. A 30 -ga cannula was placed $7.3 \mathrm{~mm}$ below dura to reach the rostral zona compacta of the substantia nigra. The 6OHDA $\mathrm{HBr}(2.0 \mu \mathrm{g} / \mu \mathrm{l})$ was dissolved in cold $0.9 \%$ saline-ascorbate solution $(0.1 \mathrm{mg} / \mathrm{ml})$. After $1 \mathrm{~min}, 4 \mu \mathrm{l}$ of the 6 -OHDA solution was infused gradually over $10 \mathrm{~min}$, and the cannula was left in place an additional $2 \mathrm{~min}$ after the infusion ended.

Eight additional rats were used as controls. Control rats received intranigral infusions of the saline-ascorbate vehicle solution, without 6-OHDA, using the same procedure. Half of both groups of rats also received injections of desipramine $(20 \mathrm{mg} / \mathrm{kg}$, i.p.) $30 \mathrm{~min}$ before surgery, and each rat was also implanted with chronic oral cannulae for reasons described elsewhere (Berridge, Venier, \& Robinson, 1989).

\section{Maintenance}

Rats were housed on a 14:10 h light:dark cycle. Postsurgical aphagia was carefully monitored. To prevent dehydration, each rat was intubated with $10 \mathrm{ml}$ water twice on the day after surgery. The rats had free access throughout to chow pellets and water and to a palatable cereal mash. Rats that ate neither food pellets nor cereal mash were classified as aphagic. Rats that ate either any pellets or mash were classified as nonaphagic for the purposes of this study. Any rat that lost body weight was intubated each day with $10 \mathrm{ml}$ of a liquid diet (sweetened condensed milk, water, vitamins) for every $5 \mathrm{~g}$ of weight lost, up to a maximum of three intubations per day.

\section{Behavioral Testing}

Grooming sequences were elicited from rats by spraying them with a light water mist, beginning after 7 days of recovery from surgery. Each rat was placed in a transparent test chamber, under which a mirror was positioned to reflect a view of the head and face of the rat into the zoom lens of a video camera. The rats were videotaped daily in 30-min sessions until at least a total of $10 \mathrm{~min}$ of continuous grooming had been taped for each rat.

\section{Chain-Completion Analysis}

Videotaped grooming sequences were analyzed in slow motion by observers blind to the experimental condition of the rats. Syntactic chains were identified first at 1/30 normal speed and then transcribed frame by frame using the graphic grooming notation system as in Berridge and Fentress (1987a, 1987b). Syntactic chains were defined by the serial occurrence of four phases: (1) a bout of five to nine elliptical strokes of small amplitude centered over the nose $(6-7 \mathrm{~Hz})$; (2) a single unilateral (or asymmetric bilateral) stroke or short series of strokes ascending to the dorsal border of the mystacial vibrissae; (3) a repeated series of large-amplitude strokes, typically bilateral and symmetrical with respect to forepaw trajectories; and (4) tucking of the head and shifting of the body to begin a bout of ventrolateral body licking (Figure 1). Criterion for chain completion in this study was the serial occurrence of all four phases in correct order within $5 \mathrm{sec}$ of the initiating Phase 1 bout of rapid ellipses. 


\section{Histology}

Eight aphagic rats with 6-OHDA lesions and 4 rats from the vehicle-control group were used for striatal dopamine-depletion analysis. The rats were decapitated, and their brains were removed and cooled in iced saline within $40 \mathrm{sec}$.

After 1 min of cooling, each brain was sliced as in Heffner et al. (1980), the striatum was bilaterally extracted by micropunch, placed in $\mathrm{HClO}_{4}$, homogenized, centrifuged, frozen, and analyzed within 2 weeks for dopamine and dopamine metabolites by highperformance liquid chromatography (Robinson, Becker, Young, Akil, \& Casteñeda, 1987).

\section{RESULTS}

6-OHDA injections into the substantia nigra produced periods of aphagia ranging from 2 to 30 days. The concentration of striatal dopamine in aphagic rats averaged approximately $15 \%$ of the control value (control rats mean $\pm S E M=17 \pm 1.43 \mathrm{ng}$ dopamine/mg wet tissue; 6OHDA rats $=2.61 \pm 1.69 \mathrm{ng} / \mathrm{mg}$ ).

Fur wetting elicited prolonged bouts of grooming in all rats. Depletion of brain dopamine levels by 6-OHDA did not diminish the amount of time that rats spent in grooming. In fact, rats that had been treated with 6-OHDA spent significantly more time grooming than did control rats [control mean $\pm S E M=24.5 \pm 4.2 \mathrm{sec}$ of grooming per minute of observation vs. $6-\mathrm{OHDA}=38.4 \pm 3.5 \mathrm{sec}$; $F(1,34)=4.55, p<.05]$. Similarly, the rate at which the rats initiated syntactic chains (defined by the occurrence of Phase 1 ellipses followed by Phase 2 strokes) was not diminished by dopamine depletion. Control and 6OHDA rats did not differ in the absolute rates at which they began syntactic chains [control $=0.45 \pm 0.08$ chains initiated per minute of observation vs. $6-\mathrm{OHDA}=0.51$ $\pm 0.06 ; F(1,34)=0.37]$. Even in terms of relative rates of chain initiation (relative to time spent in actual grooming), the control and 6-OHDA groups differed only marginally [control $=1.25 \pm 0.16$ chains per minute of actual grooming vs. $6-\mathrm{OHDA}=0.86 \pm 0.21 ;[F(1,34)=$ $3.00, p=.09$ ]. The percentage of initiated chains that were successfully completed was reduced, however, in 6-OHDA rats relative to controls [control $=87.5 \pm 3.2$; $6-\mathrm{OHDA}=69.8 \pm 5.1 ; F(1,34)=4.79, p<.05]$. Disrupted chains followed the same pattern as that seen in disruptions caused by striatopallidal lesions (Berridge \& Fentress, 1987b): the rats initiated and completed Phase 1 and often continued to Phases 2 and 3. Disruption of the pattern typically occurred during the series of largeamplitude, bilateral strokes that constitute Phase 3 (Figure 2). It is noteworthy that these interruptions did not usually halt the grooming bout but generally led immediately to a continuation of sequentially flexible facial grooming, just as in striatal lesion disruptions (Berridge \& Fentress, 1987b). Yet the rats did not lose the capacity to engage in Phase 4: the 6-OHDA rats did not show an overall reduced incidence of paw or body licking as a grooming component [control $=47 \%$ of grooming actions vs. $6-\mathrm{OHDA}=39 \% ;[F(1,34)=2.28, p>.1]$. These observations support the conclusion that both le- sions can disrupt the sequential organization of grooming without removing the capacity to produce grooming actions.

It appeared that the degree of chain disruption was not distributed randomly among the 6-OHDA rats, but rather seemed associated with the severity of aphagia that was induced by dopamine depletion. A correlation analysis between the number of days of aphagia and the chaincompletion rate for each rat showed that this was true. The length of aphagia induced by 6-OHDA was correlated positively with the percentage of disrupted syntactic chains [Spearmans tho $=0.40, t(25)=2.2, p<.05]$. Inspection of the data suggested further that a "critical threshold" for aphagia existed at roughly 6 days, which could be used to predict whether a rat's completion of syntactic chains would be impaired. To test this, the 6OHDA rats were divided into aphagic (days of aphagia $\leq 6 ; n=19$ ) or temporary (days of aphagia $\leq 5 ; n=$ 8 ) categories, and chain completion was reanalyzed. Chain-completion rates differed by category $[F(2,32)=$ $6.35, p<.01]$ in a way that supported the notion that chaining was linked to a critical severity of aphagia: 6OHDA rats that were aphagic for 6 or more days completed significantly fewer chains $(61 \% \pm 5 \%)$ than did either control (88\% $\pm 3 \%$; Newman-Keuls, $p<.01)$ or temporary 6-OHDA rats $(90 \% \pm 4 \% ; p<.01]$, whereas the control and temporary 6-OHDA categories did not differ from one another (Figure 3). Finally, separate Spearman's correlations were calculated between chain completion and aphagia, and between chain completion and striatal dopamine levels, for only those rats in the aphagic group. These analyses did not show a significant relationship between these variables, once the 6-day criterion had been exceeded (rho $<0.25$ for each).

\section{DISCUSSION}

A minimum degree of integrity among nigrostriatal projections is required for the syntactic sequencing of grooming chain actions. The disruption of syntactic chaining by 6-OHDA is not accompanied by a general reduction in the overall amount of grooming. This preservation of overall grooming levels is consistent with previous reports that grooming need not be reduced (and may even be enhanced) by brain dopamine manipulation (e.g., Dunn, Alpert, \& Iversen, 1984; Whishaw \& Dunnett, 1985 ) or by pharmacological manipulation of related neurotransmitter systems (e.g., Dunn, Berridge, Lai, \& Yachabach, 1987). Rats also retain full capacity to initiate syntactic chains at rates comparable to normal after brain dopamine depletion. However, there is a marked impairment in the rate of syntactic chain completion after 6-OHDA administration. This impairment of syntactic efficacy is linked in a stepwise fashion to the wellknown impairment of feeding that follows dopamine depletion (e.g., Ungerstedt, 1970, 1971). Only 6-OHDA injections that produce a substantial degree of aphagia, in this case aphagia of at least 6 days, appear sufficient 
CONTROL

(Vehicle SN Injection)

COMPLETED CHAINS

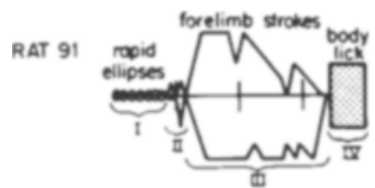

RAT 92
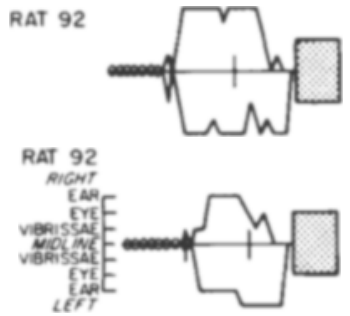

RAT 93

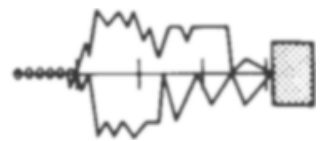

RAT 93

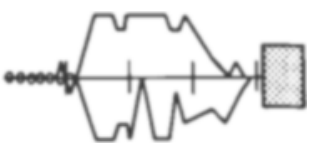

RAT 94
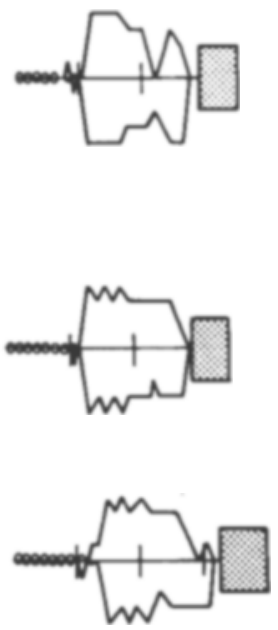

RAT 98

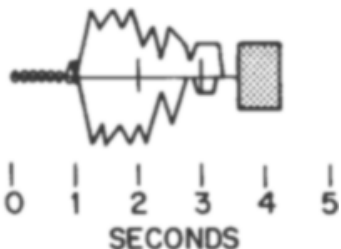

DOPAMINE DEPLETED

(6.OHDA SN Injection)

INCOMPLETE CHAINS

RAT 119

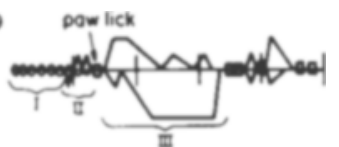

RAT 12
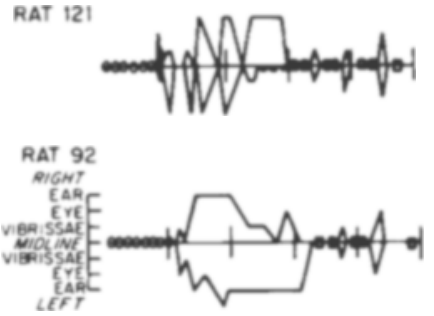

RAT 172

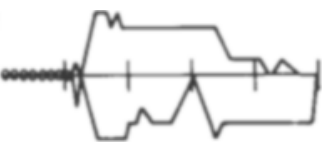

RAT 172

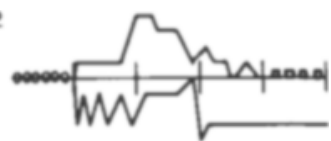

RAT 173

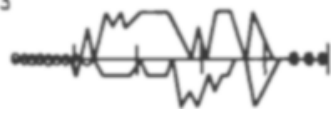

COMPLETEO CHAINS

RAT 119

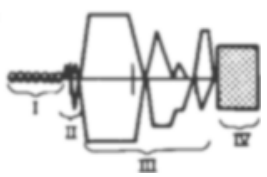

RAT 121

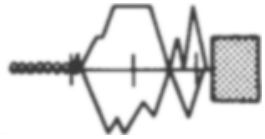

RAT 173

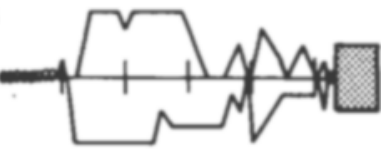

$\begin{array}{llllll}1 & 1 & 1 & 1 & 1 & 1 \\ 0 & 1 & 2 & 3 & 4 & 5\end{array}$ SECONDS

Figure 2. Notated examples of actual syntactic chains shown by vehicle-control (left panel) or dopamine-depleted (right panel) rats. Notation symbols are as in Figure 1. Syntactic phases are marked in the top chain of each column. 


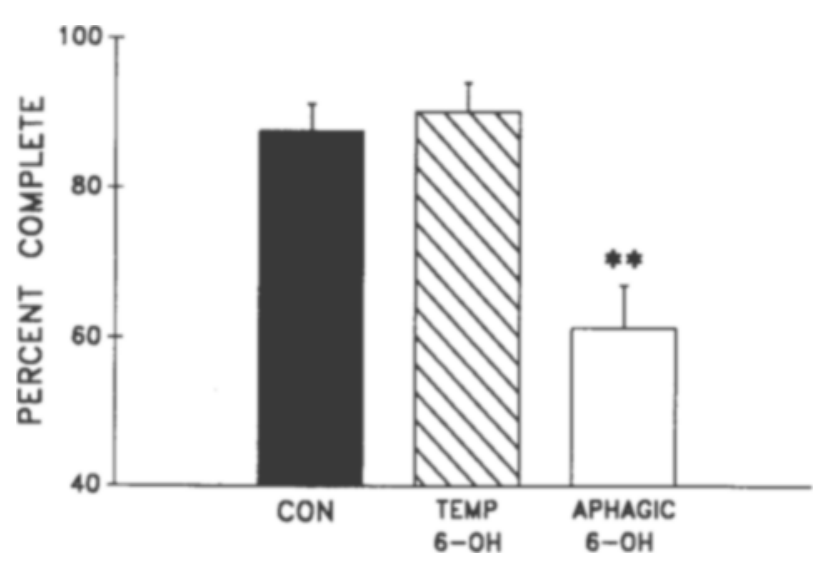

Figure 3. Percentage of chains completed $(M \pm S E M)$ by control rats and by 6-OHDA-lesion rats that showed either severe aphagia (aphagia for 6 days or more following lesion) or temporary aphagia (aphagia for 5 days or less). **Significant difference $(p<.01)$ from other groups.

to disrupt sequential chain completion. This threshold of aphagia relationship to sequence disruption appears similar to the threshold of dopamine depletion that has been described for aphagia itself after 6-OHDA administration (e.g., Stricker \& Zigmond, 1976).

These results support the idea that nigrostriatal circuits contribute to behavioral sequencing, and reinforce the point that their contribution is made as a coordinated system of neural elements working together. For this natural action chain, damage either to the intrinsic striatal neurons that constitute the targets of ascending dopamine fibers (as in Berridge \& Fentress, 1987b) or to the substantia nigra source of these fibers (as in the present study) reduces the reliability of syntactic chain execution.

The substantia nigra focus of the 6-OHDA injections in this study would have limited the population of affected dopamine neurons to those of midbrain origin, but would not have been specific to a neuronal subpopulation targeted to any particular striatal region. Different striatal regions may show considerable functional (e.g., Fairley \& Marshall, 1986; Iversen, 1984; Pisa, 1988; Pisa \& Schranz, 1988) and anatomical heterogeneity (e.g., Malach \& Graybiel, 1987; Nauta \& Domesick, 1984). It is conceivable that a study using focused lesions, which would be more specific than the massive striatal dopamine depletion used here, would reveal the existence of a crucial nigrostriatal subcircuit. In addition, it is not yet possible to tell whether the close association between the motivational deficit of aphagia and the motor or sensorimotor deficit of sequencing occurred because the two deficits are mediated by separate subcircuits, each of which is similarly depleted by a 6-OHDA injection, or because a single neural dopamine system is actually responsible for both behavioral functions. It can be noted from previous results that chain disruption was not linked closely to aphagia following intrinsic striatal damage by kainic acid, although certain other sensorimotor changes were (chain initiation, choreic paw treading) (see Berridge \& Fentress, 1987b; Berridge et al., 1988).

\section{Comparison of Neural Manipulations of Syntactic Chaining}

A growing body of data exists regarding the effects of neural manipulations on the execution of natural syntactic chain sequences in grooming. These manipulations range from the removal of facial somatosensory feedback by peripheral deafferentation, to central neurotoxin lesions of the forebrain and midbrain, to the complete isolation of the brainstem by transection at levels ranging from the caudal hypothalamus down to the rostral medulla oblongata. Each of these studies has been conducted using similar testing and analysis procedures, and legitimate comparisons can be made of the various outcomes. Such comparisons may allow us to build a more complete "neural systems" understanding of how natural sequential patterns are generated and controlled by the brain. For this purpose, and to place the present observations on 6OHDA effects in better perspective, data from this and earlier studies were explicitly compared in a statistical analysis.

The consequences of eliminating somatosensory feedback from the face during chaining $(n=8)$ were taken from the deafferentation study of Berridge and Fentress (1987a), which examined the effects of bilateral transection of the sensory maxillary (face and nose) and mandibular (jaw and tongue) branches of the trigeminal nerve. The effects on chaining from loss of intrinsic striatopallidal neurons, induced by intrastriatal injections of $1 \mu \mathrm{g}$ kainic acid in either the anterior or the posterior corpus striatum were taken from Berridge and Fentress (1987b). Anterior and posterior striatopallidal lesions resulted in equivalent disruption of chain completion in that study, so data from those lesions were combined into a single striatal lesion group $(n=19)$ for this analysis. The effects of decerebration at various brainstem levels on chaining were taken from Berridge (1989). Complete isolation of the brainstem in that study by spatula transection at a level that removed the midbrain but left the pons, cerebellum, and medulla intact (i.e., a metencephalic decerebrate: suprapontine transection) produced a degree of chain disruption that was no greater than that sustained by a mesencephalic decerebrate, which did possess a midbrain and had lost merely a forebrain (supracollicular transection). Data from rats with those transections were therefore combined into a single high decerebrate category $(n=18)$ for this analysis. Transections at the pontine-medullary function, which isolated the medulla oblongata (myelencephalon) from all rostral structures, produced a very different effect on syntactic chain completion in that study, however, so rats with myelencephalic transections were considered separately here as a low decerebrate category $(n=6)$. The effects of substantia nigra 6-OHDA lesions were contributed by the aphagic ( $\geq 6$ days) 6-OHDA group from the present study $(n=19)$. Finally, surgical controls from these studies were com- 


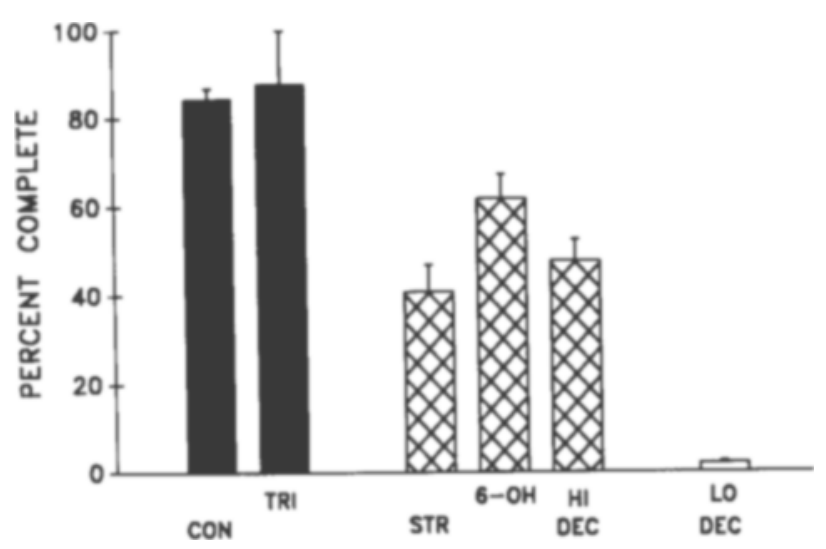

Figure 4. Percentage of chains completed $(M \pm S E M)$ by intact control (CON), trigeminal deafferented (TRN), striatopallidal lesion (STR), substantia nigra 6-OHDA lesion (6-OH), high decerebrate (HI DEC), and low decerebrate (LO DEC) groups. Similar bars denote group clusters whose members do not differ from each other but do differ from all members of other clusters. Data are from this study, Berridge and Fentress (1987a, 1987b), and Berridge (1989).

bined to form a single control group $(n=29)$. These six groups were compared for syntactic completion of grooming chains by single-factor ANOVA and Newman-Keuls tests (Figure 4).

As expected, chain-completion rates differed markedly among these six groups $[F(5,93)=26.42, p<.0001]$. Post hoc tests showed that the six different conditions assembled into the three distinct clusters shown in Figure 4. Control rats completed chains successfully at a rate of approximately $85 \%$, and this rate was not impaired by peripheral trigeminal deafferentation (Berridge \& Fentress, 1987a). Both control and trigeminal levels were significantly higher than striatal kainic acid-lesion (NewmanKeuls, $p<.01$ each), substantia nigra 6-OHDA-lesion ( $p<.05$ each), or high decerebrate $(p<.01$ each) groups. These latter three groups did not differ significantly from one another and thus formed a second cluster. This is confirmed by the fact that the five original constituent groups that made up the 6-OHDA, striatal (posterior and anterior), and high decerebrate (mesencephalic and metencephalic) categories did not vary when tested by a separate ANOVA $[F(4,51)=1.31]$. Finally, low decerebrates, which rarely or never completed chains containing all four phases, differed from every other group ( $p<.01$ each), and so formed a third cluster by themselves.

\section{GENERAL DISCUSSION}

It is not surprising that loss of either intrinsic striatal neurons or afferent dopaminergic projections can disrupt the completion of syntactic grooming chains. This chain is a complex action sequence, although stereotyped, and a considerable body of evidence exists to indicate a dependence of complex behavioral sequencing upon the integrity of nigrostriatal systems. It is somewhat surpris- ing, however, that a rat that possesses a complete forebrain, excepting only the corpus striatum or ascending substantia nigra projection to that target, should be no better able to complete syntactic chains than a rat that lacks an entire forebrain (mesencephalic decerebrate) and even midbrain (metencephalic decerebrate) in addition to nigrostriatal structures. A pontine (metencephalic) decerebrate is capable of completing chains with a success rate of approximately $40 \%$. Addition of a forebrain containing an intact nigrostriatal system (i.e., the control condition) can roughly double the effectiveness of syntactic chain completion. Addition of a forebrain minus this system (i.e., the striatal and 6-OHDA groups), however, does not significantly improve sequential performance.

The apparent fragility of forebrain function in promoting chain execution is open to a number of interpretations. The equivalence of removal of either the nigrostriatal system or the entire forebrain could reflect a preeminent role for striatal-related systems in forebrain contributions to behavioral sequencing. Conversely, it remains possible that many unrelated types of forebrain damage will prove capable of disrupting syntactic chaining. Whether nigrostriatal systems do play a special role in this regard should become clearer when more is known about the localization of the chaining function within subregions of the corpus striatum (e.g., Fairley \& Marshall, 1986; Pisa, 1988; Pisa \& Schranz, 1988), the role of cortical projections to the striatum, and the contributions of other forebrain structures and connections to syntactic sequences (e.g., Kolb, Whishaw, \& Schallert, 1977).

A related issue is the nature of the function contributed by nigrostriatal systems. The basic sequential structure of the syntactic chain can be specified by an isolated brainstem, as seen in midbrain and pontine decerebrates, and this generative sufficiency of the hindbrain might indicate that the forebrain's contribution is not one of syntactic rule generation but rather of rule implementation. One possible mechanism of implementation is sensorimotor modulation. It has been suggested that chain execution involves a phasic modulation of sensorimotor function, which is reflected by a reduction of reliance upon somatosensory guidance to shape grooming actions that occur within the chain (Berridge \& Fentress, 1987b). This reduced reliance upon sensory cues is demonstrated by the immunity of chain components from the distortions of grooming-action form induced by deafferentation (Berridge \& Fentress, 1986). It is thus reasonable to posit that chain implementation involves a hierarchical switching among sensory-guided and centrally patterned control signals. The striatum is an excellent candidate for performing such sensorimotor switching functions (see Lidsky et al., 1985; Schneider \& Lidsky, 1987).

An alternative to the "implementation by modulation" hypothesis is the possibility that nigrostriatal/forebrain systems actually participate in the sequential generation of syntactic patterns rather than acting to modulate other generator systems. The demonstration that brainstem circuits are capable of generating syntactic sequences does 
not by itself rule out an auxiliary role for the corpus striatum in pattern generation, although it does show that the striatum is neither the sole generator of such patterns nor even an essential element of a closed pattern-generating circuit. The sequential pattern of notated chains produced by midbrain, pontine, and medullary decerebrates has been observed to be consistent with the possibility that brainstem pattern-generating circuits may be organized as a degenerate or parallel system distributed along the rostro-caudal axis of the hindbrain (Berridge, 1989). A distributed, parallel system of sequential pattern generation might in principle extend rostrally to include striatalbased circuits. If this were true, then nigrostriatal systems could act as partially redundant pattern generators, unnecessary for basic pattern specification but still important to facilitate execution and to bring completion rates to normal levels. As yet, there is less evidence to support a "degenerate patterning" role for nigrostriatal systems than exists for a "sensorimotor modulating" function (see Schneider \& Lidsky, 1987) in syntactic chaining, but both can be retained as legitimate hypotheses to guide future investigations.

\section{Conclusion}

Ascending dopamine projections from the substantia nigra are essential to the role of striatopallidal systems in organizing stereotyped chain sequences of grooming. Loss of a substantial portion of this system reduces the effective completion of chains to an extent equivalent to that produced by large lesions of the corpus striatum itself. Dopamine projections appear to contribute to this sequencing function in a stepwise manner: depletion by 6-OHDA beyond a critical level, linked to the severity of induced aphagia (approximately 6 days), disrupts chain completion. When 6-OHDA lesions do not produce a degree of aphagia that exceeds this critical threshold, however, chaining is not impaired. Finally, comparisons with other studies reveal that the loss of either component of the nigrostriatal system disrupts chain completion as effectively as does loss of the entire forebrain. The nigrostriatal system thus appears to play a crucial role in forebrain coordination of this stereotyped natural sequence.

\section{REFERENCES}

AberCrombie, E. D., \& Jacobs, B. L. (1985). Dopaminergic involvement in the processing of sensory information in the striatum. Brain Research, 358, 27-33.

Aldridge, J. W., ANDerson, R. J., \& MurPhy, J. T. (1980). The role of the basal ganglia in controlling a movement initiated by a visually presented cue. Brain Research, 192, 3-16.

ANDERSon, M. E., Horack, F. B. (1985). Influence of the globus pallidus on arm movements in monkeys: 3 . Timing of movementrelated information. Journal of Neurophysiology, 54, 433-448.

Benecke, R., RothWell, J. C., Dick, J. P. R., DAY, B. L., \& MARSDEN, C. D. (1987). Disturbance of sequential movements in patients with Parkinson's disease. Brain, 110, 361-379.

BerRIDGE, K. C. (1989). Progressive degradation of serial grooming chains by descending decerebration. Behavioural Brain Research, 33, 241-253.

Berridge, K. C., Fentress, J. C. (1986). Contextual control of trigeminal sensorimotor function. Journal of Neuroscience, 6, 325-330.

Berridge, K. C., \& Fentress, J. C. (1987a). Deafferentation does not disrupt natural rules of action syntax. Behavioural Brain Research, 23, 69-76.

BerRidge, K. C., \& Fentress, J. C. (1987b). Disruption of natural grooming chains after striatopallidal lesions. Psychobiology, 15, 336-342.

Berridge, K. C., Fentress, J. C., \& Parr, H. (1987). Natural syntax rules control action sequence of rats. Behavioural Brain Research, $23,59-68$.

Berridge, K. C., Fentress, J. C., \& Treit, D. (1988). A triggered hyperkinesia induced in rats by lesions of the corpus striatum. Experimental Neurology, 99, 259-268.

Berridge, K. C., Venier, I. L., Robinson, T. E. (1989). A tastereactivity analysis of 6-OHDA-induced aphagia: Implications for arousal and anhedonia hypotheses of dopamine function. Behavioral Neuroscience, 103, 36-45.

Brunner, R. S., Kornhuber, H. H., Seemüller, E., Suger, G., \& WALLESCH, C.-W. (1982). Basal ganglia participation in language pathology. Brain \& Language, 16, 281-299.

BURY, D., \& SCHMIDT, W. J. (1987). Effects of systemically and intrastriatally injected haloperidol and apomorphine on grooming, feeding and locomotion in the rat. Behavioral Processes, 15, 269-283.

Caligiuri, M. P., \& ABbs, J. H. (1987). Response properties of the perioral reflex in Parkinson's disease. Experimental Neurology, 98 , 563-572.

Cools, A. R. (1985). Brain and behavior: Hierarchy of feedback systems and control of input. In P. P. G. Bateson \& P. H. Klopfer (Eds.), Perspectives in ethology (Vol. 6, pp. 109-168). New York: Plenum.

Crutcher, M. D., DeLong, M. R. (1984). Single cell studies of the primate putamen: 1 and 2. Experimental Brain Research, 53, 233-258.

DeLong, M. R. (1971). Activity of pallidal neurons during movement. Journal of Neurophysiology, 34, 414-427.

Divac, I., Oberg, R. G. E., \& RosenKilde, C. E. (1987). Patterned neural activity: Implications for neurology and neuropharmacology. In J. S. Schneider \& T. I. Lidsky (Eds.), Basal ganglia and behavior: Sensory aspects of motor functioning (pp. 61-70). Toronto: Hans Huber.

Dunn, A. J., AlPert, J. E., \& Iversen, S. D. (1984). Dopamine denervation of frontal cortex or nucleus accumbens does not affect ACTHinduced grooming behavior. Behavioural Brain Research, 12, 307-315.

Dunn, A. J., Berridge, C. W., LaI, Y. I., \& Yachabach, T. L. (1987). CRF-induced excessive grooming behavior in rats and mice. Peptides, 8, 841-844.

DUNNETT, S. B., \& IVERSEN, S. D. (1982). Sensorimotor impairments following kainic acid and 6-hydroxydopamine lesions of the neostriatum. Brain Research, 248, 121-127.

Evarts, E. V., KimURA, D., WURTZ, R. M., \& Mikosaka, O. (1984). Behavioral correlates of activity in basal ganglia neurons. Trends in Neuroscience, 7, 447-453.

Fairley, P. C., \& Marshall, J. F. (1986). Dopamine in the lateral caudate-putamen of the rat is essential for somatosensory orientatio. Behavioral Neuroscience, 100, 652-663.

FENTREss, J. C. (1972). Development and patterning of movement sequences in inbred mice. In J. Kiger (Ed.), The biology of behavior (pp. 83-132). Corvallis, OR: Oregon State University Press.

HefFner, T. G., Hartman, J. A., \& Versteeg, D. H. G. (1976). A rapid method for the regional dissection of the rat brain. Pharmacology, Biochemistry \& Behavior, 13, 453-456.

Huston, J. P., Morgan, S., Lange, K. W., \& Steiner, H. (1986). Neuronal plasticity in the nigrostriatal system of the rat after unilateral removal of vibrissae. Experimental Neurology, 93, 380-389.

IVERSON, S. D. (1979). Behavior after neostriatal lesions in animals. In I. Divac \& R. G. E. Öberg (Eds.), The neostriatum (pp. 195-212). New York: Pergamon. 
IVERSON, S. D. (1984). Behavioral effects of manipulations of basal ganglia neurotransmitters. In D. Evered \& M. O'Conner (Eds.), Functions of the basal ganglia (pp. 183-200). London: Pitman.

Jaspers, R., SChWARTz, H., Sontag, K. H., Cools, A. R. (1984). Caudate nucleus and programming behavior in cats: Role of dopamine in switching motor pattems. Behavioural Brain Research, 14, 17-28.

Kolb, B., Whishaw, I. Q., Schallert, T. (1977). Aphagia, behavior sequencing and body weight set point following orbital frontal lesions in the rat. Physiology \& Behavior, 19, 93-103.

LASHLEY, K. S. (1951). The problem of serial order in behavior. In L. A. Jeffress (Ed.), Cerebral mechanisms in behavior (pp. 112-156). New York: Wiley

Lidsky, T. I., Manetto, C., \& Schneider, J. S. (1985). Consideration of sensory factors involved in motor functions of the basal ganglia. Brain Research Reviews, 9, 133-146.

Malach, R., Graybiel, A. M. (1987). The somatic sensory cortical striatal projection: Patchwork of somatic sensory zones in the extrastriosomal matrix. In J. S. Schneider \& T. I. Lidsky (Eds.), Basal ganglia and behavior: Sensory aspects of motor functioning (pp. 11 16). Lewiston, NY: Hans Huber.

MARsden, C. D. (1980). The enigma of the basal ganglia and movement. Trends in Neuroscience, 3, 284-287.

MARSDEN, C. D. (1982). The mysterious motor function of the basal ganglia: The Robert Wartenberg lecture. Neurology, 32, 514-539.

Marshall, J. F.. Turner, B. H., \& Teitelbaum, P. (1971). Sensory neglect produced by lateral hypothalamic syndrome. Science, 174, 523-539.

Nauta, W. J. H., \& Domesick, V. B. (1984). Afferent and efferent relationships of the basal ganglia. Functions of the Basal Ganglia: Ciba Foundation Symposium 107 (pp. 3-23). London: Pitman.

PISA, M. (1988). Motor somatotopy in the striatum of rat: Manipulation, biting, and gait. Behavioural Brain Research, 27, 21-35.

Pisa, M., \& Schranz, J. A. (1988). Dissociable motor roles of the rat's striatum conform to a somatotopic model. Behavioral Neuroscience, $102,429-440$.

Richmond, G., \& SACHS, B. D. (1978). Grooming in Norway rats: The development and adult expression of a complex motor pattern. Behaviour, 75, 82-96.

Robinson, T. E., Becker, J. B., Young, E. A., Akil, H., \& CASTAÑEDA, E. (1987). The effects of footshock stress on regional brain dopamine metabolism and pituitary $\beta$-endorphin release in rats previously sensitized to amphetamine. Neuropharmacology, 26, 679-691.

Rolls, E. T., \& Willuams, G. V. (1987). Sensory and movement-related neuronal activity in different regions of the primate striatum. In J. S. Schneider \& T. I. Lidsky (Eds.), Basal ganglia and behavior: Sensory aspects of motor function (pp. 37-59). Toronto: Hans Huber.
SChallert, T., Hall, S. (1988). "Disengage" sensorimotor deficit following apparent recovery from unilateral dopamine depletion. Behavioural Brain Research, 30, 15-24.

Schallert, T., Whishaw, 1. Q., De Ryck, M., a Teitelbaum, P. (1978). The postures of catecholamine-depletion catelepsy: Their possible adaptive value in thermoregulation. Physiology \& Behavior, 21. 817-820.

SCHмid, W. J. (1984). L-dopa and apomorphine disrupt long but not short behavioral chains. Physiology \& Behavior, 33, 671-680.

SCHNEIDER, J. S. (1984). Basal ganglia role in behavior: Importance of sensory gating and its relevance to psychiatry. Biological Psychiatry, 19. 1693-1710.

SCHNEIDER, J. S. (1987). Basal ganglia-motor influences: Role of sensory gating. In J. S. Schneider \& T. I. Lidsky (Eds.), Basal ganglia and behavior: Sensory aspects of motor functioning (pp. 103-121). New York: Hans Huber.

SChneider, J. S., Diamond, S. G., \& Markham, C. H. (1986). Deficits in oro-facial sensorimotor function in Parkinson's disease. Annals of Neurology, 19, 275-282.

SCHNEIDER, J. S., \& LIDSKY, T. I. (Eds.) (1987). Basal ganglia and behavior: Sensory aspects of motor function. Toronto: Hans Huber.

Stelmach, G. E. Worringham, C. J., Strand, E. A. (1987). The programming and execution of movement sequences in Parkinson's disease. International Joumal of Neuroscience, 36, 55-65.

Stricker, E. M., Zigmond, M. J. (1976). Brain catecholamines and the lateral hypothalamic syndrome. In D. Novin, W. Wyrwicka, \& G. Bray (Eds.), Hunger: Basic mechanisms and clinical implications (pp. 19-32). New York: Raven.

UNGERSTEDT, U. (1970). Is interruption of the nigrostriatal dopamine system producing the "lateral hypothalamic syndrome"? Acta Physiologica Scandinavica, 80, 35A-36A.

UNGERSTEDT, U. (1971). Aphagia and adipsia after 6-hydroxydopamine induced degeneration of nigrostriatal dopamine system. Acta Physiologica Scandinavica (Suppl. 367), 95-122.

Whishaw, I. Q., \& DunNeTt, S. B. (1985). Dopamine depletion, stimulation, or blockade in the rat disrupts spatial navigation and locomotion dependent upon beacon or distal cues. Behavioural Brain Research, 18, 11-29.

Whishaw, I. Q., O'Conner, W. T., Dunnett, S. B. (1986). The contributions of motor contex, nigrostriatal dopamine and caudateputamen to skilled forelimb use in the rat. Brain, 109, 805-843.

Whishaw, I. Q., TomiE, J.-A. (1988). Food wrenching and dodging: A neuroethological test of cortical and dopaminergic contributions to sensorimotor behavior in the rat. Behavioral Neuroscience, 102, 110-123.

(Manuscript received November 4, 1988; revision accepted for publication May 18, 1989.) 